\title{
Patient-prosthesis mismatch after mitral valve replacement: Myth or reality?
}

\author{
Pasquale Totaro, $\mathrm{MD}^{\mathrm{a}}$ and Vincenzo Argano, $\mathrm{MD}^{\mathrm{b}}$
}

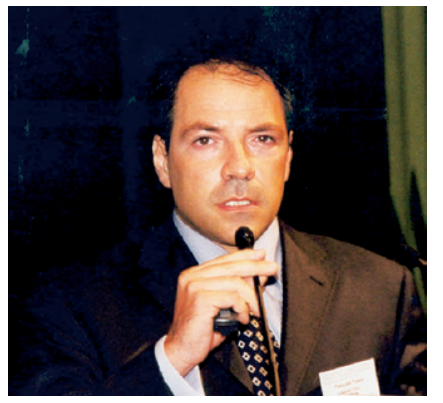

Dr Totaro
From the Cardiac Surgery Division, Civic Hospital, Brescia, Italy ${ }^{\mathrm{a}}$; and the Department of Thoracic and Cardiovascular Surgery, Villa Maria Eleonora Hospital, Palermo, Italy. ${ }^{\text {b }}$

Received for publication Feb 2, 2007; revisions received March 19, 2007; accepted for publication April 11, 2007.

Address for reprints: Pasquale Totaro, MD, Via San Vincenzo, 38, 20123 Milan, Italy (E-mail: ptotaro@yahoo.com).

J Thorac Cardiovasc Surg 2007;134:697-701 $0022-5223 / \$ 32.00$

Copyright @ 2007 by The American Association for Thoracic Surgery

doi:10.1016/j.jtcvs.2007.04.031
Objective: Determining the risk of patient-prosthesis mismatch after mitral valve replacement is still controversial. In this study, we aimed to clarify incidence and clinical implications of such a complication. The accuracy of preoperative prediction of patient-prosthesis mismatch using published in vitro hemodynamic parameters was also investigated.

Methods: Ninety-two patients who underwent mitral valve replacement and received Carpentier-Edwards stented bioprosthesis (Edwards Lifesciences, LLC, Irvine Calif) were enrolled. Hemodynamic performances were evaluated at discharge, and the incidence of in vivo patient-prosthesis mismatch (indexed effective orifice area $\leq 1.2 \mathrm{~cm}^{2} / \mathrm{m}^{2}$ ) was evaluated. Correlation between in vivo patient-prosthesis mismatch and predicted patient-prosthesis mismatch, based on previously published in vitro hemodynamic parameters, was also investigated.

Results: Five patients died within 30 days of the operation (5.4\% mortality). Mean prosthesis size was $29.8 \pm 2$. Mean postoperative effective orifice area and indexed effective orifice area $\left(2.5 \pm 0.8 \mathrm{~cm}^{2}\right.$ and $1.5 \pm 0.4 \mathrm{~cm}^{2} / \mathrm{m}^{2}$, respectively) compared favorably with those predicted in vitro $\left(2.2 \pm 0.7 \mathrm{~cm}^{2}\right.$ and $1.3 \pm 0.5 \mathrm{~cm}^{2} / \mathrm{m}^{2}$, respectively). In the subgroup of patients receiving prosthesis size of 27 or smaller, the difference reached statistical significance $(2.47 \pm 0.83$ and $1.61 \pm 0.7$ for postoperative and predicted effective orifice areas, respectively; $P<.001)$. Postoperative patient-prosthesis mismatch was recorded in 8 patients (8.6\%), comparing favorably with the predicted patient-prosthesis mismatch (39\% for overall population and $80 \%$ for patients receiving prosthesis size $\leq 27$ ). No significant correlation between size of prosthesis and early hemodynamic and clinical outcomes was shown.

Conclusions: In our study, stented mitral bioprostheses showed satisfactory postoperative hemodynamic performance, even in smaller prosthesis sizes ( $\leq 27$ $\mathrm{mm}$ ). Risk of in vivo postoperative patient-prosthesis mismatch seems to be less relevant than preoperative risk prediction based on in vitro data. Further studies are needed to evaluate the potential clinical impact of mitral patient-prosthesis mismatch.

$\mathrm{T}$ he term patient-prosthesis mismatch (PPM) was introduced in the late 1970s by Rahimtoola ${ }^{1}$ to describe the condition in which the effective orifice area (EOA) of the prosthetic valve inserted into the patient was not matching the area of the native valve, thus causing an abnormal residual pressure gradient across the valve with obstruction to ventricular outflow or inflow, or both. Since then, several studies have been designed and carried out to better clarify the cutoff value for PPM to occur, as well as the clinical relevance of such a complication. The majority of these studies, however, have concentrated on PPM after aortic valve replacement. ${ }^{2-7}$ It is only in the recent era that the clinical consequence of mitral PPM has been considered. ${ }^{8}$ 


\author{
Abbreviations and Acronyms \\ EOA = effective orifice area \\ MEOA $=$ mitral effective orifice area \\ MEOAI $=$ indexed mitral effective orifice area \\ MVR = mitral valve replacement \\ PPM = patient-prosthesis mismatch
}

In this study we evaluate early postoperative hemodynamic performance and early clinical outcomes in patients undergoing MVR with a stented bioprosthesis to better clarify the real risk and the early clinical relevance of mitral PPM.

\section{Patients and Methods}

Data from 92 consecutive patients (male 39\%, mean age $74 \pm 4$ years) who underwent MVR with a biologic prosthesis, as an isolated or combined procedure, were prospectively collected. Only emergency operations were excluded and no patients were excluded on the basis of preoperative left ventricular function or pulmonary hypertension.

Two types of Carpentier-Edwards stented bioprostheses (Perimount pericardial and SAV porcine; Edwards Lifesciences, LLC, Irvine Calif) were used according to surgeon preference. Patient characteristics are summarized in Table 1 . Preoperative and postoperative hemodynamic performances were recorded for all survivors and compared with the in vitro data published by the manufacturer for the implanted prosthesis. Incidence of postoperative PPM was evaluated and correlated to the predicted incidence of PPM. Finally, postoperative hemodynamic performance and clinical outcome were correlated to the size of bioprosthesis implanted.

\section{Echocardiographic Technique and Definition}

Transthoracic echocardiograms performed by an experienced cardiologist, unaware of the size of prosthesis implanted, were obtained preoperatively (within 72 hours before the operation) and postoperatively (30 days after the operation) in all patients. As previously suggested, ${ }^{9}$ the postoperative mitral effective orifice area (MEOA) was calculated by the continuity equation method. Indexed MEOA was calculated as MEOAI = MEOA/body surface area. According to the definition previously published, ${ }^{9}$ mitral patient-prosthesis mismatch was defined as MEOAI of 1.22 $\mathrm{cm}^{2} / \mathrm{m}^{2}$ or less. Systolic pulmonary artery pressure was calculated by adding the systolic right ventricular pressure derived from the tricuspid regurgitation to the estimated right atrial pressure. According to previously published data, ${ }^{10}$ pulmonary hypertension was defined as moderate for systolic pulmonary artery pressures of $40 \mathrm{~mm} \mathrm{Hg}$ or greater and severe for systolic pulmonary artery pressures of $60 \mathrm{~mm} \mathrm{Hg}$ or greater.

\section{Surgical Technique}

All procedures were performed through a standard midline sternotomy and full cardiopulmonary bypass. Antegrade cold blood cardioplegia was used as conventional myocardial protection strategy. The mitral valve was approached with a standard left
TABLE 1. Patient characteristics

$\begin{array}{lc}\text { Age (y) } & 74 \pm 4 \\ \text { Sex } & \\ \text { Male } & 36(38) \\ \text { Female } & 56(62) \\ \text { BSA }\left(\mathrm{cm}^{2} / \mathrm{m}^{2}\right) & 1.7 \pm 0.2 \\ \text { BMI }\left(\mathrm{kg} / \mathrm{m}^{2}\right) & 25 \pm 5 \\ \text { Rhythm } & \\ \text { Sinus } & 36(38) \\ \text { AF/flutter } & 56(62) \\ \text { LVEF } & \\ \text { Good (EF }>50 \%) & 28(30) \\ \text { Moderate (EF } 30 \%-50 \%) & 48(52) \\ \text { Poor (EF }<30 \%) & 16(18) \\ \text { Pulmonary hypertension } & \\ \text { Severe (PAP }>60 \mathrm{~mm} \mathrm{Hg}) & 19(20) \\ \text { Moderate (PAP }>40 \mathrm{~mm} \mathrm{Hg}) & 38(40) \\ \text { Associated procedures } & \\ \text { MVR + AVR } & 21(23) \\ \text { MVR + CABG } & 41(45)\end{array}$

$B S A$, Body surface area; $B M I$, body mass index; $A F$, atrial fibrillation; $L V E F$, left ventricular ejection fraction; $E F$, ejection fraction; $P A P$, pulmonary artery pressure; $M V R$, mitral valve replacement; $A V R$, aortic valve replacement; $C A B G$, coronary artery bypass graft.

atrial incision. Native posterior leaflet or subvalvular apparatus, or both, were preserved whenever possible. All prostheses were implanted with interrupted everting 2-0 Ethibond (Ethicon Inc, Somerville, NJ) non-pledget-supported sutures (except under specific conditions).

\section{Statistical Analysis}

Values are expressed as mean \pm standard deviation. Noncontinuous parameters were compared by the $\chi^{2}$ test or Fisher exact test when appropriate. Continuous variables were compared by the Student $t$ test for paired and unpaired data when appropriate. Simple least squared linear regression was used to test the association between continuous variables.

\section{Results}

Two patients died in the hospital (cumulative early mortality $2.5 \%$ ), and 3 patients died during 30 days of surveillance (cumulative 30-day mortality 5.4\%). Early postoperative outcome (in terms of intensive care unit stay, mechanical ventilation, and cumulative hospital stay) and postoperative hemodynamic performances are summarized in Table 2A. Postoperative hemodynamic performance measured in vivo by transthoracic echocardiography is shown in Table 2B. No significant differences were found comparing the two types of prosthesis (mean EOAI was $1.5 \pm 0.4$ and $1.4 \pm$ $0.5 \mathrm{~cm}^{2} / \mathrm{m}^{2}$ for porcine and pericardial prostheses, respectively $(P=.5)$. Average EOAI was above the limit for mitral PPM definition and EOAI less than 1.22 was obtained in only 8 patients with a cumulative incidence of PPM of $8.6 \%$ (Table 2B). Both postoperative MEOA and MEOAI compared 

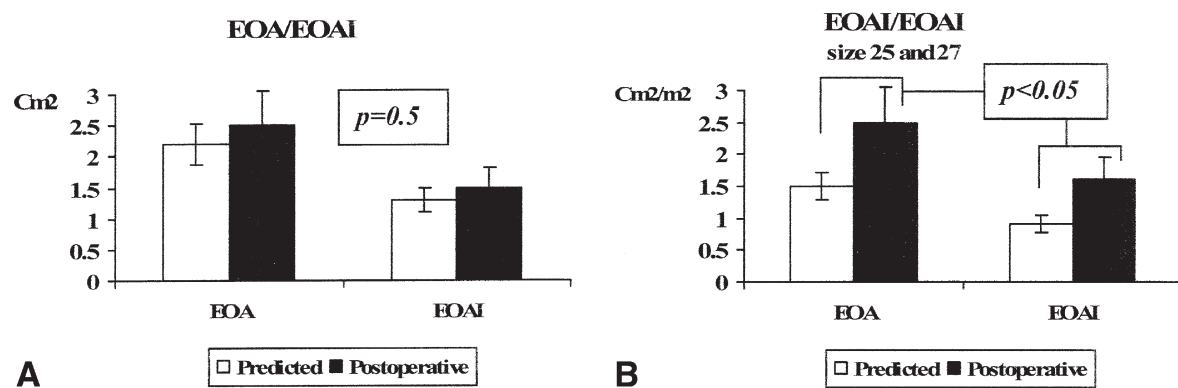

Figure 1. A, Comparison between preoperative predicted EOA and EOAI based on in vitro value published by the manufacturer and in vivo value measured postoperatively. B, Comparison between preoperative predicted EOA and EOAI in patients receiving size 25 and 27 prostheses. EOA, Effective orifice area; EOAl, indexed effective orifice area. favorably (although with no statistical significance) with the predicted value based on in vitro measurement ${ }^{11}$ (Figure 1, $A$ ). Furthermore, if we consider only patients receiving bioprosthesis sizes 25 to 27 , the differences reach statistical significance (Figure 1,B).

The incidence of postoperative PPM also compared favorably with the predicted incidence based on the in vitro value. In this respect, the difference is significant either in the overall population or in the subgroup receiving a smaller prosthesis (Figure 2). Furthermore (Figure 3), no statistically significant correlation was found between increased size of implanted prosthesis and hemodynamic performance ( $r=0.14$ for MEOA and $r=0.23$ for peak gradient). No clinical impact was shown in patients who experienced PPM. Postoperatively, at least moderate residual pulmonary hypertension was shown in 41 (47\%) patients (Table 2B), with no correlation to the size of prosthesis implanted.

\section{Discussion}

We evaluated the risk of PPM after MVR on the basis of in vivo postoperative measurement of EOAI. Our results indi-

TABLE 2A. Early postoperative clinical outcome

$\begin{array}{lc}\text { 30-day mortality } & 5(5 \%) \\ \text { ICU stay (d) } & 2.6 \pm 1.9 \\ \text { Ventilation time (d) } & 1.3 \pm 0.7 \\ \text { Total hospital stay (d) } & \\ \quad \text { Mean } & 14 \pm 12 \\ \quad \text { Median } & 10\end{array}$

ICU, Intensive care unit.

TABLE 2B. Thirty-day postoperative in vivo hemodynamic performance assessed by transthoracic echocardiography

$\begin{array}{lc}\text { MEOA }\left(\mathrm{cm}^{2}\right) & 2.4 \pm 0.9 \\ \text { MEOAI }\left(\mathrm{cm}^{2} / \mathrm{m}^{2}\right) & 1.5 \pm 0.6 \\ \text { Peak gradient }(\mathrm{mm} \mathrm{Hg}) & 11 \pm 8 \\ \text { Mean gradient }(\mathrm{mm} \mathrm{Hg}) & 5 \pm 1 \\ \text { PPM } & 8(8.6 \%) \\ \text { Residual pulmonary hypertension } & 41(47 \%)\end{array}$

MEOA, Mitral effective orifice area; MEOAI, mitral effective orifice area index; $P P M$, patient-prosthesis mismatch. cate that the predicted risk of mitral PPM, based on in vitro measurement, significantly exceeds the real risk of PPM after MVR, even when small-sized bioprostheses are used. Furthermore, our study failed to show any significant correlation between increased size of prosthesis implanted and improved early hemodynamic and clinical outcome.

PPM was first described by Rahimtoola ${ }^{1}$ in 1978 as a clinical syndrome after valve replacement with a prosthesis too small compared with the patient's body surface area. This concept has become extremely popular in the past two decades, and several articles have been published addressing this issue. The vast majority of such studies ${ }^{2-7}$ have focused on PPM after aortic valve replacement, inasmuch as the prosthesis implanted in this position is generally smaller. In this respect, several aspects related to the definition, ${ }^{3,4}$ the consequences, ${ }^{6,7}$ and the prevention ${ }^{6,7}$ of PPM have been addressed. Several steps forward have been made, therefore, regarding the better understanding of aortic PPM. Conversely, regarding mitral PPM, only limited experience has been reported so far.

In our study, we aimed to evaluate the potential risk for increased incidence of PPM using stented bioprostheses,

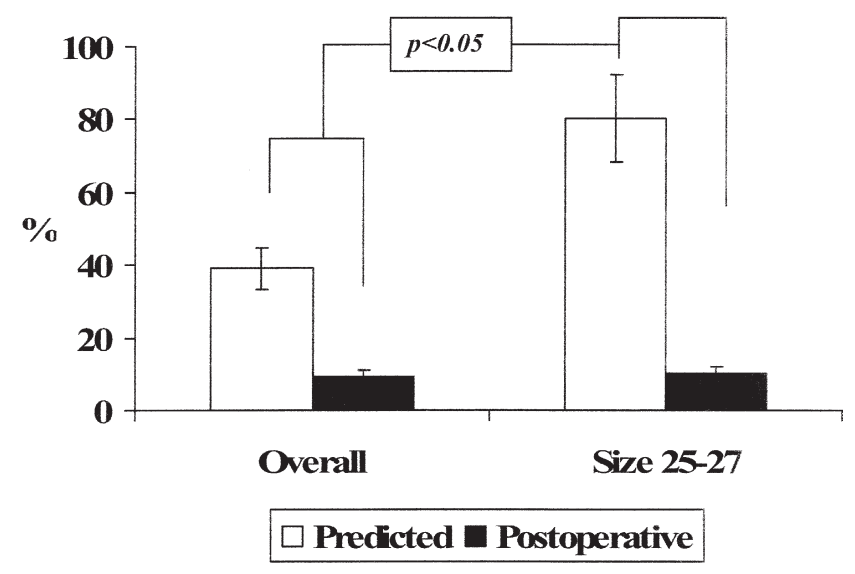

Figure 2. Comparison between preoperative predicted PPM based on in vitro value published by the manufacturer and in vivo PPM measured postoperatively (specificity $31 \%$, sensitivity $6 \%$ ). PPM, Patient-prosthesis mismatch. 

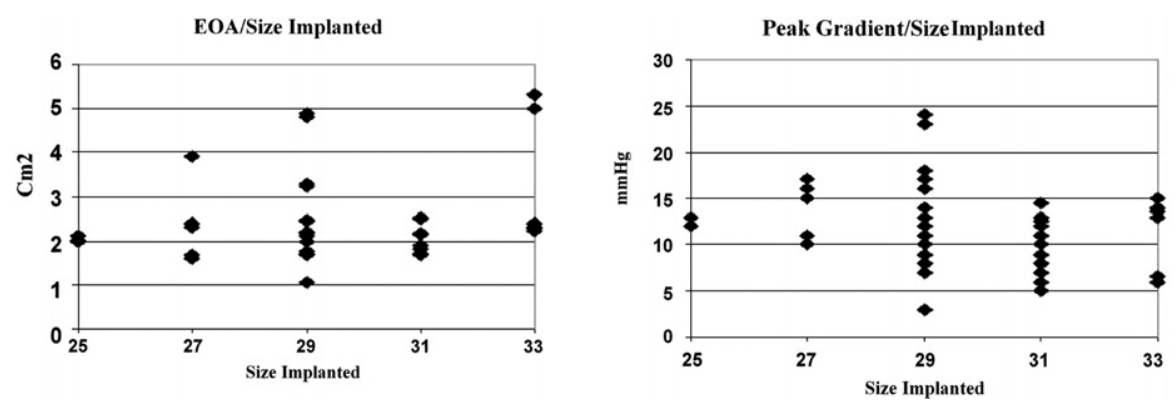

Figure 3. Linear regression: No significant correlation is shown between increased size of bioprosthesis implanted and postoperative hemodynamic performance. Left, Postoperative pressure gradient. Right, Postoperative EOA.

comparing early postoperative hemodynamic performance with the in vitro predicted hemodynamic performance. We used a definition of PPM based on calculated in vivo postoperative MEOAI, which remains, despite a certain degree of variability resulting from associate factors, ${ }^{12}$ the most valuable parameter to evaluate PPM. To reduce prosthesisrelated bias, we restricted the study to patients receiving only Edwards Lifesciences bioprostheses (pericardial or porcine) used for many years and with a well-documented durability and reliability. ${ }^{13-15}$

The first important finding in our study was the lack of correlation between increased prosthesis size and improved postoperative hemodynamic performance. We confirmed, therefore, findings from Firstenberg and associates, ${ }^{16}$ who showed a trend but not a significant correlation between increased prosthesis size and postoperative EOA after MVR with a Carpentier-Edwards Perimount bioprosthesis. Badano and coauthors ${ }^{17}$ also showed no correlation between increased size of prosthesis and improved hemodynamic performance, but they evaluated only postoperative pressure gradients in patients after MVR with a mechanical prosthesis. Our experience is based on both pericardial and porcine bioprostheses (from the same company); however, we did not show any difference related to the type of prosthesis, despite previous studies that suggested improved flow geometry in pericardial compared with porcine valves. ${ }^{18,19}$ An important finding of our study is the correlation between in vivo and in vitro evaluation of hemodynamic performance of mitral bioprostheses. Despite the good linear correlation that has been shown between in vivo and in vitro EOA for each prosthesis, ${ }^{7,9}$ the latest is usually superior. In our experience, postoperative in vivo EOA was, conversely, comparable with the predicted in vitro value. Furthermore, considering only patients receiving the smaller bioprostheses (25 and 27), in vivo hemodynamic performances were significantly superior to those predicted in vitro. This finding is interesting, especially considering the opposite observation reported for aortic bioprostheses, and deserves further evaluation. We could only suppose that the postimplantation behavior of a prosthesis in the mitral position can be influenced by different physiologic aspects, significantly more than in the aortic position.
Favorable hemodynamic performance reflects the incidence of postoperative PPM in our series, significantly lower than the predicted risk based on in vitro measurement. Our results, therefore, failed to confirm recent experience from $\mathrm{Li}$ and coauthors, ${ }^{8}$ who reported a high incidence of PPM after MVR (71\%). At least three main characteristics differentiate the series from that of $\mathrm{Li}$ and colleagues, however: (1) the low percentage of patients receiving a bioprosthesis (only 16\%), (2) the high percentage of patient receiving a small-sized prosthesis (52\%), and (3) the time of the echocardiographic data collection (median follow-up time of 43 months). These specific conditions could in part explain the differences reported in our experience. On the other hand, Chan and associates (personal communication, 2006) reported a $13.8 \%$ incidence of PPM (based on in vitro data) in 884 patients undergoing MVR mainly with mechanical prostheses $(75 \%)$. In our study, furthermore, the incidence of PPM was not correlated to the size of bioprosthesis. On the basis of our experience, therefore, we would not support extreme efforts to implant a prosthesis bigger than size 25 in the patient with a small or calcified annulus. In this case, the increased surgical risk seems unjustified by a real reduction of PPM incidence. It seems clear, however, that a homogenous method of hemodynamic performance evaluation is the first step toward a better understanding of the real risk of mitral PPM. In our minds, postoperative evaluation of EOAI is mandatory for definition of PPM. As far as the clinical relevance of PPM was concerned, in our series only 8 patients had PPM, with no implications on clinical outcome. Despite our experience being limited to 30 days' follow-up, previous experiences ${ }^{20,21}$ already failed to show clinical relevance of implantation of a "small" prosthesis, at least in terms of recurrence of heart failure at 5 years' follow-up. Also, no effect on early or late mortality of prosthesis-related factors after MVR was shown by Fernandez and coauthors. ${ }^{22}$ On the other hand, Yazdanbakhsh and coauthors, ${ }^{23}$ using geometric valve area and a cutoff for PPM definition equal to the 10th percentile, showed significant impact of PPM on early death but not on late followup. In their experience, however, the cutoff, based on a very low percentile, could have selected patients with "extreme" mismatch. Concerning clinical aspects of mitral PPM, Li 
and coauthors ${ }^{8}$ recently showed a significant difference in persistence of pulmonary hypertension (at a mean follow-up of 43 months) in patients with mitral PPM when compared with those not having PPM. Even though we failed to confirm this finding (in our series residual pulmonary hypertension was not correlated to size of prosthesis or postoperative PPM), we have to consider that our experience is limited to 1-month follow-up and, as a previous study clearly demonstrated, ${ }^{23}$ pulmonary artery hypertension does not always regress immediately after surgery. Furthermore, as previously discussed, the group from $\mathrm{Li}$ and coauthors ${ }^{8}$ included $71 \%$ of patients having PPM. The correlation between size of prosthesis implanted, postoperative PPM, and persistence of pulmonary hypertension therefore deserves further evaluation as well as the potential correlation between persistence of pulmonary hypertension and longterm clinical outcome.

\section{Conclusions}

When evaluated by postoperative EOAI, PPM after MVR seems to be less frequent than that previously reported. In vivo hemodynamic performances of bioprostheses can be superior to those calculated in vitro, especially in patients with smaller prostheses. Clinical relevance of mitral PPM, moreover, has to be confirmed with more extensive studies based on the postoperative diagnosis of PPM.

\section{References}

1. Rahimtoola SH. The problem of valve prosthesis-patient mismatch. Circulation. 1978;58:20-4.

2. Rahimtoola SH, Murphy E. Valve prosthesis-patient mismatch. A long term sequela. Br Heart J. 1981;45:331-5.

3. Blais C, Dumesnil JG, Baillot R, Simard S, Doyle D, Pibarot P. Impact of valve prosthesis-patient mismatch on short-term mortality after aortic valve replacement. Circulation. 2003:26;108:983-8.

4. Gillinov AM, Blackstone EH, Rodriguez LL. Prosthesis-patient size: measurement and clinical implications. $J$ Thorac Cardiovasc Surg. 2003;126:313-6. Comment on: J Thorac Cardiovasc Surg. 2003;126: $337-43$.

5. Tasca G, Brunelli F, Cirillo M, DallaTomba M, Mhagna Z, Troise G, et al. Impact of valve prosthesis-patient mismatch on left ventricular mass regression following aortic valve replacement. Ann Thorac Surg. 2005;79:505-10.

6. Howell NJ, Keogh BE, Barnet V, Bonser RS, Graham TR, Rooney SJ, et al. Patient-prosthesis mismatch does not affect survival following aortic valve replacement. Eur J Cardiothorac Surg. 2006;30:10-4.

7. Flameng W, Meuris B, Herijgers P, Herregods MC. Prosthesis-patient mismatch is not clinically relevant in aortic valve replacement using the Carpentier-Edwards Perimount valve. Ann Thorac Surg. 2006;82: 530-6.
8. Li M, Dumesnil JG, Mathieu P, Pibarot P. Impact of valve prosthesispatient mismatch on pulmonary arterial pressure after mitral replacement. J Am Coll Cardiol. 2005;45:1034-40.

9. Dumesnil JG, Honos GM, Lemieux M, Beauchemin J. Validation and applications of mitral prosthetic valvular area calculated by Doppler echocardiography. Am J Cardiol. 1990;65:1443-8.

10. McQuillan BM, Picard MH, Leavitt M, Weyman AE. Clinical correlates and reference intervals for pulmonary artery systolic pressure among echocardiographically normal subjects. Circulation. 2001;104: 2797-802.

11. Marquez S, Hon RT, Yoganathan AP. Comparative hydrodynamic evaluation of bioprosthetic heart valves. J Heart Valve Dis. 2001;10: 802-11.

12. Khan S, Mitchell RS, Derby GC, Oyer PE, Miller DC. Hemodynamic comparison of Hancock and Carpentier-Edwards mitral bioprosthetic valves. Circulation. 1990;82(5 Suppl):IV75-81.

13. Jamieson WR, Miyagishima RT, Burr LH, Lichtenstein SV, Fradet GJ, Janusz MT. Carpentier-Edwards porcine bioprostheses: clinical performance assessed by actual analysis. J Heart Valve Dis. 2000;9: 530-5.

14. Jamieson WR, Burr LH, Munro AI, Miyagishima RT. CarpentierEdwards standard porcine bioprosthesis: a 21-year experience. Ann Thorac Surg. 1998;66(6 Suppl):S40-3.

15. Chaudhry MA, Raco L, Muriithi EW, Bernacca GM, Tolland MM, Wheatley DJ. Porcine versus pericardial bioprostheses: eleven-year follow up of a prospective randomized trial. J Heart Valve Dis. 2000;9:429-37; discussion 437-8.

16. Firstenberg MS, Morehead AJ, Thomas JD, Smedira NG, Cosgrove DM, Marchand MA, for the Carpentier-Edwards PERIMOUNT Investigators. Short-term hemodynamic performance of the mitral Carpentier-Edwards PERIMOUNT pericardial valve. Ann Thorac Surg. 2001;71:S285-8.

17. Badano L, Mocchegiani R, Bertoli D, DeGaetano G, Carratino L, Pasetti L, et al. Normal echocardiographic characteristics of the Sorin Bicarbon bileaflet prosthetic heart valve in the mitral and aortic positions. J Am Soc Echocardiogr. 1997;10:632-43.

18. Pelletier C, Chaitman B, Bonan R, Dyrda I. Hemodynamic evaluation of the Carpentier-Edwards standard and improved annulus bioprosthesis. In: Cohn LH, Gallucci V, editors. Cardiac bioprosthesis: Proceedings of the Second International Symposium. New York: Yorke Medical Books; 1982. p. 96.

19. Black MM, Cochrame TT, Lawford PV. Design and flow characteristics. In: Bodner E, Frater R, editors. Replacement cardiac valves. New York: McGraw-Hill; 1992. p. 1.

20. Lorusso R, Beghi C, Gerometta PS, Russo C, Gherli T, Casari S, et al. Mitral valve replacement with small prosthesis (size 23-25) in adult subjects: long-term postoperative results from a multicentre retrospective study. Circulation. 2002;106(Suppl II):674.

21. Ruel M, Rubens F, Master R, Pipe AL, Bedard P, Mesana TG. Late incidence and predictors of persistent or recurrent heart failure in patients with mitral prosthetic valves. $J$ Thorac Cardiovasc Surg. 2004;128:278-83.

22. Fernandez J, Chen C, Laub GW, Anderson WA, Bradik OB, Murphy $\mathrm{MM}$, et al. Predictive value of prosthetic valve area index for early and late clinical results after valve replacement with the St. Jude Medical valve prosthesis. Circulation. 1996;94(Suppl):II109-12.

23. Yazdanbakhsh AP, van den Brink RB, Dekker E, de Mol BA. Small valve area index: its influence on early mortality after mitral valve replacement. Eur J Cardiothorac Surg. 2000;17:222-7. 